ORIGINAL ARTICLE

\title{
Intensive education combined with low tech ergonomic intervention does not prevent low back pain in nurses
}

\author{
J Hartvigsen, S Lauritzen, S Lings, T Lauritzen
}

Occup Environ Med 2005;62:13-17. doi: 10.1136/oem.2003.010843

See end of article for authors' affiliations

.....................

Correspondence to: Dr J Hartvigsen, Nordic Institute of Chiropractic and Clinical Biomechanics, Klosterbakken 20, 5000

Odense C, Denmark;

i.hartvigsen@nikkb.dk

Accepted 10 July 2004
Aims: To evaluate the effectiveness of an intensive educational and low-tech ergonomic intervention programme aimed at reducing low back pain (LBP) among home care nurses and nurses' aids.

Methods: In 1999, 345 home care nurses and nurses' aids in four Danish municipalities were studied. Participants in two municipalities constituted the intervention group and participants in the other two served as the control group. In the intervention group, participants were divided into small groups, each of which was assigned one specially trained instructor. During weekly meetings participants were educated in body mechanics, patient transfer, and lifting techniques, and use of low-tech ergonomic aids. In the control group, participants attended a one time only three hour instructional meeting. Information on LBP was collected using the Standardised Nordic Questionnaire supplemented with information on number of episodes of LBP and care seeking due to LBP during the past year.

Results: A total of 309 nurses and nurses' aids returned the questionnaire at baseline and 255 at follow up in August 2001. At follow up, no significant differences were found between the two groups for any of the LBP variables, and both groups thought that education in patient transfer techniques had been helpful. Within group changes in LBP status was not related to the intervention or to satisfaction with participating in the project.

Conclusions: Intensive weekly education in body mechanics, patient transfer techniques, and use of lowtech ergonomic equipment was not superior to a one time only three hour instructional meeting for home care nurses and nurses' aids. ow back pain (LBP) is a major public health problem throughout the western world, ${ }^{12}$ and the prevalence of -LBP appears to be even higher for nurses and nurses' aids than for women of similar age in the general population. ${ }^{34}$ In addition, the risk for occupational back accidents in nurses and nurses' aids is higher than for working women in other jobs. $^{5}$

Patient transfer involves adjusting the patient in bed, transferring a patient from bed to chair or wheelchair or vice versa, or transferring a patient from bed or chair to toilet. ${ }^{6}$ These manoeuvres have consistently been linked to low back injuries in nurses and nurses' aids, ${ }^{6-14}$ and are perceived to be the physically most stressful tasks performed by these occupations. ${ }^{15}{ }^{16}$ Not surprisingly, efforts have been made to prevent low back injuries following patient handling, including education in lifting techniques and back school, ${ }^{17} 18$ ergonomic interventions and mechanical equipment, ${ }^{19}$ and individually designed physical training programmes and stress management. ${ }^{20}$ The majority of studies evaluating preventive interventions have, however, been dealing with nurses and nurses' aids in the hospital setting and not in home care, and overall the interventions have proved to be of little long term benefit. ${ }^{21}$

The objective of the present study was to evaluate the effectiveness of an intensive educational and low-tech ergonomic intervention programme aimed at reducing LBP among home care nurses and nurses' aids in two Danish municipalities, using home care nurses and nurses' aids from two neighbouring municipalities as controls. Outcome measures at the two year follow up were number of days with self reported LBP during the past year, number of episodes of LBP, and care seeking for LBP during the past year.

\section{METHODS}

\section{Participants}

In August 1999, baseline questionnaires were sent to all 345 home care nurses and nurses' aids in four municipalities in the county of Aarhus, Denmark. Home care nurses are provided routinely and free of charge in Denmark for patients who do not require hospitalisation but need assistance with personal care and/or daily medical aid or supervision. The four municipalities are all primarily rural with middle to higher income families, and situated within a one hour drive from a larger metropolitan area. Nurses and nurses' aids in two municipalities formed the intervention group and nurses and nurses' aids in the other two municipalities constituted the control group. In August 2001, follow up data were collected again using questionnaires. All questionnaires were administered by the employer and filled out at the worksite.

\section{Interventions}

In the intervention group, nurses and nurses' aids were divided into eight groups of 8-12. One nurse or nurses' aid was educated as instructor for each group. The instructors were educated by and had access to advice from a physiotherapist with special knowledge and experience in rational body mechanics and lifting techniques according to the Bobath principle ${ }^{22}$ (box 1). To ensure optimal implementation, instructors had a minimum of one hour per week during two years to educate, supervise, and enforce messages about lifting techniques and body mechanics to all members in their group. This included instruction and reinforcement in using low-tech ergonomic aids such as plastic sheets for sliding instead of lifting patients and slings for use when carrying was unavoidable. At the meetings participants were also encouraged to provide feedback and to constructively 
criticise colleagues that had been observed to transfer patients inappropriately. Four times during the first seven months, two hour meetings were held between a psychologist and the individual groups and the instructor to reinforce the messages regarding patient transfer techniques and optimal body mechanics. The role of the psychologist was to facilitate group discussions and to work with particularly sceptical or silent participants.

Every six weeks, one hour meetings were held between all the group instructors, physiotherapists, and the management to discuss progress and difficulties in the project.

In the control group, nurses and nurses' aids attended a one time only three hour instruction in lifting technique conveying a similar message. In the control group low-tech ergonomic devices were not available. No additional information or follow up was provided in this group.

\section{Objectives}

To evaluate whether intensive education combined with a low-tech ergonomic programme was superior to the usual instructional meeting in improving existing LBP or preventing future low back problems.

\section{Outcomes}

Information on the number of days with LBP during the past year at baseline and at follow up was assessed using the Standardised Nordic Questionnaire by asking participants how many days they had experienced LBP (pain, tenderness, stiffness, or other trouble) during the preceding year. ${ }^{23}$ Possible answers were "0 days", "1-7 days", 8-30 days", "more than 30 days but not daily", and "daily". Information on the number of episodes of LBP during the past year ("How often have you had low back pain during the past year?". Possible answers were "none", "one", "a couple", "a couple of times per month", "at least weekly"), seeking of treatment during the past year ("Have you during the past year received any treatment (for instance bed rest, exercises, massage, injections, traction, manipulation, surgery, or other forms of treatment) for low back pain?"'), and satisfaction with participation in the project was collected at follow up using

Box 1: Key features of the advice enforced in the intervention group

- Let the patient do as much as possible. Assist-do not take over.

- When you have to assist: Move one body part at a time whenever possible.

- Avoid carrying-use your imagination, transfer technique, and maybe slings.

- Plan ahead and use aids.

- Prepare the person-tell them what you are going to do.

- Good, natural movements and balance are more important than carrying positions.

- Find areas of friction and reduce friction against the foundation.

- Let your bodyweight do the work instead of your arms and back.

- Wear loose clothing that does not restrict your movements, and good shoes with rubber soles.

- Good working technique alone does not solve all problems-planning and organisational development is equally important. a self administered questionnaire. Information on self rated general health was collected using standard questions from the Danish version of the SF-36 questionnaire..$^{24}$

\section{Sample size}

All home care nurses and nurses' aids in the four municipalities were invited to participate in the study. No further sample size calculations were performed.

\section{Statistical methods}

The two groups were compared at baseline for age, sex, and self rated health using $\chi^{2}$ tests. For comparison between groups, the number of days with LBP during the past year at baseline and at follow up and the number of episodes of LBP during the past year at follow up were illustrated graphically and compared, again using $\chi^{2}$ tests.

Logistic regression models were used to estimate the association between improving during the study period and the intervention and the number of days with LBP during the past year at baseline. First, a dichotomous outcome variable was constructed; it was coded 1 if the participant reported less days with LBP during the past year at follow up compared to baseline, and 0 if the participant reported the same or more days with LBP during the past year at follow up compared to baseline. Regression models including intervention group and number of days with LBP, and self rated health at baseline and age as covariates were constructed and odds ratios (OR) were estimated. Likewise, logistic regression models were used to estimate the effect of the intervention on the number of episodes with LBP during the past year and seeking of treatment for LBP during the past year. All models investigating effect of the intervention were controlled for number of days with LBP during the past year and self rated health at baseline and age. To account for the possible nonindependence of observations for participants from the four counties, participants from each county were analysed as a cluster in all regression models. For the odds ratios, 95\% confidence intervals not including 1 and $p$ values $<0.05$ were considered significant. All analyses were performed using the STATA 7 statistical software package. ${ }^{25}$

\section{RESULTS}

\section{Participation}

Overall, $316(92 \%)$ of the nurses and nurses' aids returned the questionnaire at baseline and 255 (83\% of the baseline participants) at follow up two years later (fig 1). At baseline, the intervention and control groups were similar with respect to age (range 21-64 in both groups), sex (all were female), and number of days with LBP during the past year. The control group rated their own health significantly poorer than the intervention group $(p=0.025$, Fisher's exact test $)$ (table 1). The baseline characteristics for the women participating at baseline and not at follow up were not

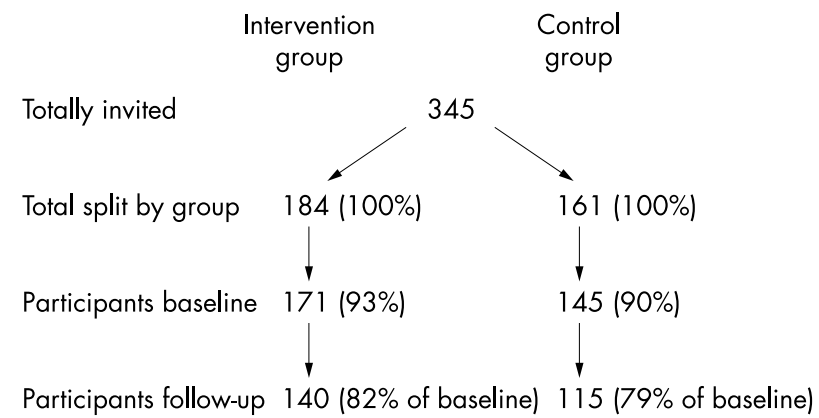

Figure 1 Flow of participants. 


\begin{tabular}{|c|c|c|}
\hline & Intervention group & Control group \\
\hline$n$ & 171 & 145 \\
\hline Age (mean, range) & $44.6,21-64$ & $44.4,21-64$ \\
\hline Sex & All female & All female \\
\hline \multicolumn{3}{|c|}{ Days with LBP during past year* } \\
\hline 0 days & 43 (38 to 53 ) & $39(31$ to 48$)$ \\
\hline 1-7 days & $30(23$ to 37$)$ & $29(22$ to 37$)$ \\
\hline $8-30$ days & $10(6$ to 15$)$ & 11 (7 to 18$)$ \\
\hline$>30$ days & $10(6$ to 15$)$ & 11 (7 to 18$)$ \\
\hline Daily & $7(2$ to 8$)$ & 10 (4 to 14$)$ \\
\hline \multicolumn{3}{|l|}{ Self rated health $\dagger$} \\
\hline Excellent & $38(31$ to 46$)$ & 25 (18 to 33$)$ \\
\hline Good & 50 (43 to 58$)$ & $54(46$ to 63$)$ \\
\hline Fair & $12(7$ to 17$)$ & $20(13$ to 27$)$ \\
\hline Bad & 0 & $1(0$ to 4$)$ \\
\hline Very bad & 0 & 0 \\
\hline
\end{tabular}

${ }^{*}$ Difference between intervention and control $\left(\chi^{2}\right.$ test $) p=0.764$. Results

tDifference between intervention and control $\left(\chi^{2}\right.$ test) $p=0.119$. Results expressed as \% (95\% Cl).

significantly different from the follow up participants for any of these variables (data not shown).

\section{Comparison between groups}

At follow up, no significant differences were found between the intervention and the control group with respect to number of days with LBP during the past year $\left(\mathrm{p}<0.88, \chi^{2}\right.$ year ( $p<0.84, \chi^{2}$ test) (fig 3 ), and seeking of examination or treatment due to LBP during the past year $\left(p=0.76, \chi^{2}\right.$ test). Both groups thought that education in patient transfer techniques was helpful and a larger proportion of participants in the intervention group thought that enough had been done during the study period. This difference in opinion was, however, not significant and did not affect any of the LBP outcomes (data not shown).

\section{Factors associated with improvement}

Thirty nine per cent of participants in the intervention group had improved at least one category in the "number of days with LBP during the past year" variable at follow up compared to baseline, versus $32 \%$ in the control group. The improvement in category was, however, not associated with the intervention but rather with the number of days with LBP at baseline (table 2). Improvement in the "number of expressed as \% $(95 \% \mathrm{Cl})$. test) (fig 2), the number of episodes with LBP during the past

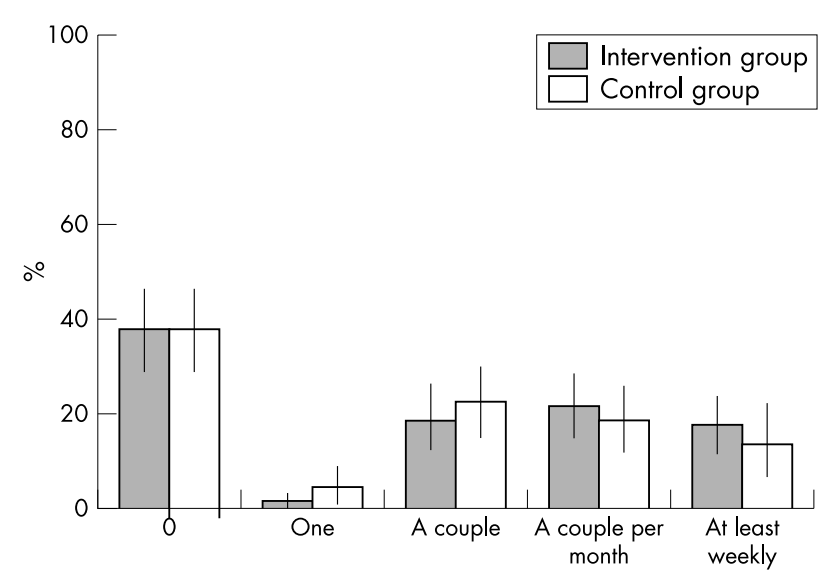

Figure 3 Intervention and control group compared for number of episodes of LBP during the past year at follow up.

episodes of LBP during the past year" variable was also not associated with the intervention or days with LBP at baseline (table 2). Finally, seeking treatment during the past year at follow up was also not associated with the intervention but significantly associated with the number of days with LBP during the past year at baseline (table 2).

\section{DISCUSSION}

Education and back school are commonly used in the workplace in order to prevent injuries to the low back. The results of this two year prospective controlled study suggest that an intensive educational and low-tech ergonomic programme is no more effective than a minimal educational effort in reducing or preventing LBP. In fact, the number of days with LBP, the number of episodes of LBP, and the number of participants seeking care for LBP were more likely explained by the number of days with LBP during the past year at baseline, than by participating in the intervention. This is best explained by a strong regression towards the mean.

Failure to detect any effect of a programme may be due to inadequate sample size, differences in the basis or status of the two groups at baseline, inadequate implementation of the programme, too short study or follow up period, or fundamental lack of efficacy of the programme. We do not believe that the first three factors played a significant role in the present study. First, since the observed effect was very small, we do not believe that increasing the sample size

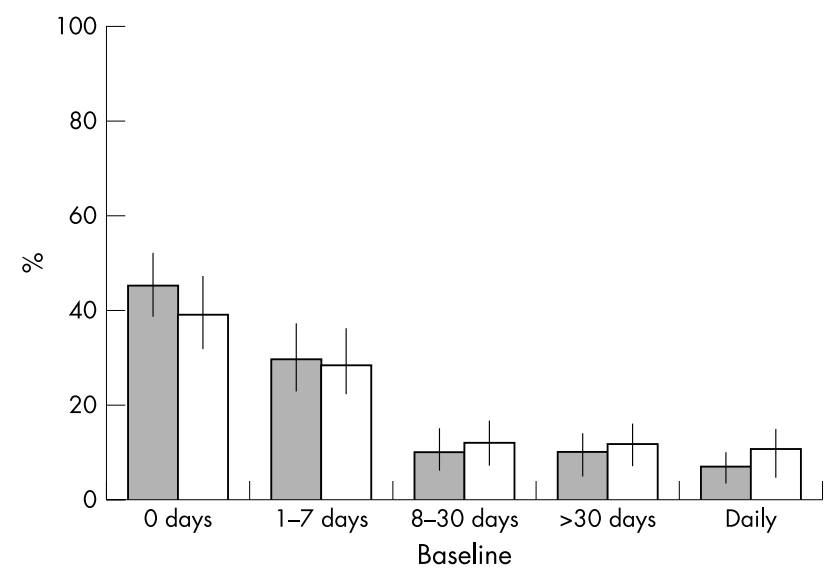

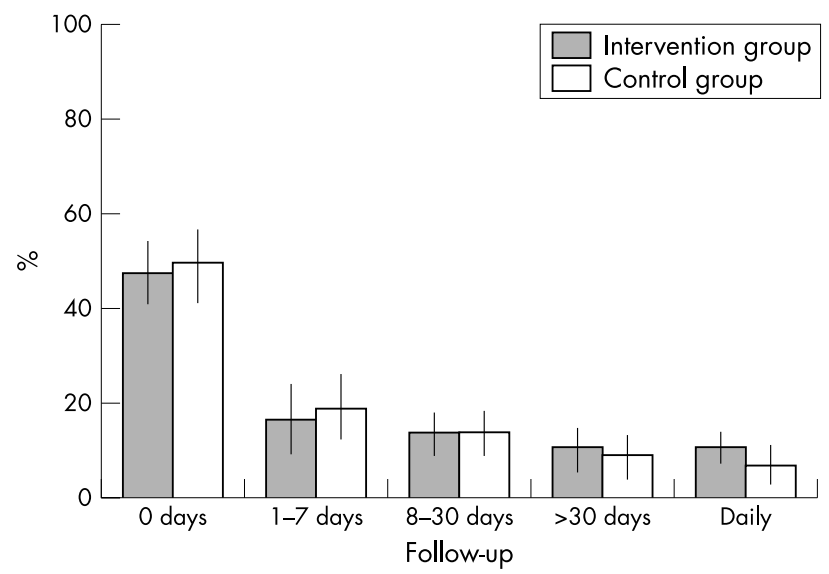

Figure 2 Intervention and control group compared for number of days with LBP during the past year at baseline and at follow up. 
Table 2 Odds ratios (OR) for association between fewer days with LBP and fewer episodes of LBP during the past year at follow up and seeking of treatment for LBP at follow up, and the intervention and number of days with LBP during the past year at baseline

\begin{tabular}{lll}
\hline & $\begin{array}{l}\text { Intervention } \\
\text { OR }(95 \% \mathrm{Cl})^{*}\end{array}$ & $\begin{array}{l}\text { Duration of LBP at } \\
\text { baseline } \\
\text { OR }(95 \% \mathrm{Cl}){ }^{*}\end{array}$ \\
\hline $\begin{array}{l}\text { Improving one category in number } \\
\text { of days with LBP during past year }\end{array}$ & $0.98(0.52$ to 1.85$)$ & $4.57(3.22$ to 6.46$)$ \\
$\begin{array}{l}\text { Improving one category in number } \\
\text { of episodes with LBP during past year }\end{array}$ & $1.01(0.49$ to 1.53$)$ & $1.03(0.62$ to 1.72) \\
$\begin{array}{l}\text { Seeking of treatment during past } \\
\text { year at follow up }\end{array}$ & $1.14(0.69$ to 1.89$)$ & 1.69 (1.38 to 2.07) \\
\hline *Controlled for the opposite variable and age. & \\
\hline
\end{tabular}

would have altered the outcome of the study, even though we did not perform any further power calculations since increasing the number of participants was not an option. Second, there was no difference between the two groups at baseline for the variables sex, age, number of days with LBP during the past year, and self rated health. Furthermore, the geographic proximity of the participating municipalities ensured that regional differences (that is, urban versus rural population) did not affect the results. Third, we believe that the programme was implemented efficiently even though we did not perform a proper process evaluation. A large number of instructional and motivational meetings were held both for the participants and for the instructors, and more than $94 \%$ of the participants in the intervention group stated that they used relevant transfer techniques in their daily work. Curiously, the corresponding proportion in the control group was $93 \%$. We thus consider it unlikely that an increased number of teaching sessions would alter the results in favour of the intervention. On the contrary, the large number of teaching sessions may have increased awareness of back problems and in fact augmented the problem in the intervention group. It is, however, also possible that the outcome of the study would have been different if participants were followed for a longer period of time. Maybe the effect of presumably good habits cannot be detected within the first two years after implementation. For all practical purposes, however, we suspect that at least a positive trend at the two year follow up would be present should such a long term effect indeed exist. We therefore conclude that the results of this study are most likely due to a fundamental lack of effect of this intensive educational and low-tech ergonomic programme and not due to other factors.

Maher systematically and critically reviewed 13 randomised clinical trials dealing with workplace interventions to prevent LBP. $^{26} \mathrm{He}$ concluded that there was moderate evidence that education alone was ineffective in preventing LBP in the workplace. ${ }^{26}$ In a more recent study, Fanello et al confirmed these results in a nurse population and concluded that the teaching of rational patient handling activities (including access to ergonomic equipment) were ineffective in preventing new LBP episodes when used alone, ${ }^{18}$ and Straker in a recent review concluded that there was no scientific evidence in favour of any single lifting technique. ${ }^{27}$ With the addition of the present study, we feel comfortable concluding that even though satisfaction with participation in educational programmes is high $(>90 \%$ in our sample), and even though considerable resources were used to implement the education in daily practice, little, if any, effect on LBP occurred.

Combining education in patient transfer techniques with individualised physical training programmes may provide better results according to Maher. ${ }^{26}$ However, Volinn found that results of studies investigating the effect of workplace interventions aiming at preventing low back disorders were highly dependent on the methodological quality of the study and that, in general, a much smaller effect was found in studies of higher quality, regardless of the intervention. ${ }^{28}$ Consequently, Horneil et al in a recent rigorously designed randomised clinical trial, found no effect of an individually designed physical training programme compared to a nonintervention control group in female home care personnel. ${ }^{20}$ Education in patient transfer techniques was, however, not included in the active group.

Results of programmes aiming at reducing or preventing LBP in the workplace in general and in home care nurses and nurses' aids in particular have so far been sobering. The challenge for occupational physicians is to develop new and innovative approaches and to combine already existing strategies in new ways. For researchers, the job at hand will be to evaluate the efficacy of such programmes so that truly cost effective prevention strategies can be developed. Intensive education in patient transfer techniques and lowtech ergonomic equipment does not appear to be the solution.

\section{ACKNOWLEDGEMENTS}

The authors gratefully acknowledge Lars Korsholm PhD, Department of Statistics, University of Southern Denmark, for statistical advice.

\section{Authors' affiliations}

J Hartvigsen, Nordic Institute of Chiropractic and Clinical Biomechanics, Klosterbakken 20, 5000 Odense C, Denmark

S Lauritzen, Home Care Unit, Municipality of Roende, Hovedgaden 77, 8410 Roende, Denmark

S Lings, Odense University Hospital, Department of Occupational and Environmental Medicine, Sdr. Boulevard 29, 5000 Odense C, Denmark T Lauritzen, Aarhus University, Institute for General Medical Practice, Vennelyst Boulevard 6, 8000 Aarhus C, Denmark

\section{REFERENCES}

1 Deyo RA, Cherkin D, Conrad D, et al. Cost, controversy, crisis: low back pain and the health of the public. Annu Rev Public Health 1991;12:141-56.

2 Leboeuf-Yde C, Klougart N, Lauritzen T. How common is low back pain in the Nordic population? Data from a recent study on a middle-aged Danish population and four surveys conducted in the Nordic countries. Spine 1996;21:1518-25.

3 Lagerstrom M, Hansson T, Hagberg M. Work-related low-back problems in nursing. Scand J Work Environ Health 1998;24:449-64.

4 Josephson $M$, Lagerstrom $M$, Hagberg $M$, et al. Musculoskeletal symptoms and job strain among nursing personnel: a study over a three year period. Occup Environ Med 1997; 54:681-5.

5 Engkvist IL, Hagberg M, Liden A, et al. Over-exertion back accidents among nurses' aides in Sweden. Saf Sci 1992;15:83-92.

6 Knibbe JJ, Friele RD. Prevalence of back pain and characteristics of the physical workload of community nurses. Ergonomics 1996;39:186-98.

7 Videman T, Nurminen T, Tola S, et al. Low-back pain in nurses and some loading factors of work. Spine 1984;9:400-4.

8 Harber $\mathrm{P}$, Bittet $\mathrm{E}$, Gutowski $M$, et al. Occupational low back pain in hospital nurses. J Occup Med 1985;27:518-24.

9 Venning PJ, Walter SD, Stitt LW. Personal and job-related factors as determinants of incidence of back injuries among nursing personnel. J Occup Med 1987;29:820-5. 
10 Harber P, Pena L, Hsu P, et al. Personal history, training, and worksite as predictors of back pain of nurses. Am J Ind Med 1994;25:519-26.

11 Fuortes L, Shi Y, Zhang M, et al. Epidemiology of back injury in university hospital nurses from review of workers' compensation records and a casecontrol survey. J Occup Med 1994;36:1022-6.

12 Smedley J, Egger P, Cooper C, et al. Manual handling activities and risk of low back pain in nurses. Occup Environ Med 1995;53:160-3.

13 Yassi A, Khokhar J, Tate R, et al. The epidemiology of back injuries in nurses at a large Canadian tertiary care hospital: implications for prevention. Occup Med (Lond) 1995;45:215-20.

14 Engkvist IL, Hielm EW, Hagberg M, et al. Risk indicators for reported overexertion back injuries among female nursing personnel. Epidemiology 2000;1 1:519-22.

15 Garg A, Owen B, Beller D, et al. A biomechanical and ergonomic evaluation of patient transferring tasks: wheelchair to shower chair and shower chair to wheelchair. Ergonomics 1991;34:407-19.

16 Garg A, Owen B, Beller D, et al. A biomechanical and ergonomic evaluation of patient transferring tasks: bed to wheelchair and wheelchair to bed. Ergonomics 1991;34:289-312.

17 Daltroy LH, Iversen MD, Larson MG, et al. A controlled trial of an educational program to prevent low back injuries. N Engl J Med 1997;337:322-8.

18 Fanello $S$, Jousset N, Roquelaure $Y$, et al. Evaluation of a training program for the prevention of lower back pain among hospital employees. Nurs Health Sci 2002;4:51-4.
19 Yassi A, Cooper JE, Tate RB, et al. A randomized controlled trial to prevent patient lift and transfer injuries of health care workers. Spine 2001;26:1739-46.

20 Horneij E, Hemborg B, Jensen I, et al. No significant differences between intervention programmes on neck, shoulder and low back pain: a prospective randomized study among home care personnel. J Rehabil Med $2001 ; 33: 170-6$.

21 Hignett S. Work-related back pain in nurses. J Adv Nurs 1996;23 1238-46.

22 Manning J. Facilitation of movement-the Bobath approach. Physiotherapy 1972;58:403-8.

23 Kuorinka IA, Jonsson B, Kilbom A, et al. Standardized Nordic questionnaires for the analysis of musculoskeletal symptoms. Applied Ergonomics 1987; 18:233-7.

24 Bjorner JB, Thunedborg K, Kristensen TS, et al. The Danish SF-36 Health Survey: translation and preliminary validity studies. J Clin Epidemiol 1998;51:991-9.

25 Stata Statistical Software. College Station, TX: Stata Corporation, 2000.

26 Maher CG. A systematic review of workplace interventions to prevent low back pain. Aust J Physiother 2000;46:259-69.

27 Straker LM. A review of research on techniques for lifting low-lying objects evidence for a correct technique. Work 2003;20:83-96.

28 Volinn E. Do workplace interventions prevent low-back disorders? If so, why? A methodologic commentary. Ergonomics 1999;42:258-72.

\section{$\mathrm{ECHO}$}

\section{Copycat tactics could cut company injuries}

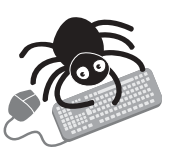

Please visit the Occupational and

Environmental Medicine website [www. occenvmed. com] for a link to the full text of this article. significant drop in occupational injuries would be attained by getting firms in the A same industry to emulate those with lower injury rates, claim researchers in Ontario, Canada. This approach would also offer a means of implementation, by enabling those responsible for reducing occupational injury to encourage managers in poorer performing firms to adopt currently available safety strategies of their better performing counterparts.

A potential drop of as much as $42 \%$ in lost time (occupational injury) across large and small firms could be realised if all firms aimed at a target of the 25th percentile of the distribution for their industry, the researchers calculated. This translates to 148477 fewer occupational injuries than the 351533 injuries actually recorded. The 25th percentile was not the lowest target but the one likely to be perceived as realistic and achievable with current safety policies and practices in use.

The study used data from the sole insurance providers for lost time injury compensation in Ontario on all insured firms in 215 rate groups-companies in the same type of business-during 1998-2001. Injury rate within each group was worked out as lost time injuries/100 full time equivalent workers/year for each firm and the 25th percentile from the distribution within the group. Comparing expected injuries against actual injuries showed the potential savings.

Occupational injury rates are still very variable across western firms in the same industry. So the researchers looked to see how much rates could be expected to drop by applying a common benchmark to them.

A Shannon HS, et al. Injury Prevention 2004;10:292-295. 